\title{
Entre memoria y conflicto. La construcción mediática de la otredad en el marco del conflicto limitrofe entre Chile y Perú
}

\author{
Memory and Conflict. The Discourse of Press in Relation \\ with the Chilean-Peruvian Conflict of Year 2005
}

\author{
Javier Mayorga Rojel \\ Luis Nitrihual Valdebenito \\ Carlos del Valle Rojas \\ Universidad de la Frontera \\ delvalle@ufro.cl
}

\begin{abstract}
Resumen
Este trabajo ${ }^{1}$ presenta los resultados de un análisis del discurso realizado a los diarios chilenos El Mercurio y La Tercera, a propósito del conflicto limítrofe chileno-peruano en el año 2005. Se establece un marco teórico que permite repensar los mass media como industrias generadoras de discursos que refuerzan valores presentes en el contexto.

En esta medida, se muestra como la visión construida desde los media, en este caso particular, contribuye a reforzar el clima de antagonismo entre estos dos países latinoamericanos, sustentado esto en una historia/memoria, que se construye en contraposición y en la cual los discursos mediáticos juegan un papel de reforzadores de estereotipos.
\end{abstract}

Palabras claves: Representación, Conflicto, Discurso, Medios de Comunicación

\begin{abstract}
In this present research we show the results of the Discourse Analysis applied to the newspapers El Mercurio and La Tercera. Its in relation with the Chilean-Peruvian conflict at the year 2005.

This article provides an theoretical framework for think the mass media as industries that reinforce the present values in the context.
\end{abstract}

\footnotetext{
1 "Representación mediática del Perú en la prensa chilena. Descripción de las lógicas y dinámicas del discurso periodístico en el marco del conflicto limítrofe-marítimo de 2005”, Investigación realizada en el Programa de Magíster en Ciencias de la Comunicación, Departamento de Lenguas, Literatura y Comunicación, Facultad de Educación y Humanidades, Universidad de La Frontera. Temuco, Chile.
} 
Based on this, we want to demonstrate as the mass media, in this particular case, it helps to strengthen the climate of antagonism between these two Latin American countries. We proponed that this is a history / memory, built in opposition, and where the mass media discourses have a role that reinforce stereotypes.

Keywords: Representation, Discourse Analysis, Mass media.

\section{Introducción}

En la actualidad el sistema de los mass media en el marco de su relación con la sociedad, forja una acción constante en el campo de sus instancias de producción/circulación que tiene como propósito la imposición de un control social que busca evitar los posibles efectos negativos desencadenados por medio de la aparición de variables imprevistas en el entorno.

Estas variables imprevistas en el entorno son las necesarias para generar el azar de los acontecimientos, donde estos últimos, al producir variaciones propias de los sistemas externos, afectan el desarrollo normal de los procesos discursivos y productivos de los medios de comunicación alineados a determinadas lógicas sociales y, en consecuencia, asientan las bases institucionales de control mediático como una forma reconocida y aplicada por los mass media para el encauzamiento de las noticias (valorización y producción del acontecimiento) o, en determinados casos donde se visualice la posibilidad que tenga un acontecimiento de sobrepasar el control, excluir de la agenda mediática el hecho acaecido.

Según este planteamiento inicial, los medios de comunicación ejecutan una complicidad a la hora de emprender las distintas etapas del proceso productivo mediático, de tal manera que el discurso institucional publicado por los diversos medios (televisión, radio y prensa escrita) tenga cierta consonancia en el marco del resguardo político, económico y cultural que se desea imprimir por medio de las variables y constantes determinadas por los propios medios.

Entonces, en el marco de la lógica de la industria mediática chilena, se observa que toda producción del discurso periodístico posee factores que participan activamente en la configuración del plano de la expresión y del contenido del mismo, por ende en el proceso discursivo que atañe directamente a la representación mediática del Perú en el discurso periodístico de los diarios ${ }^{2}$ El Mercurio $^{3}$ y La Tercera ${ }^{4}$, es factible observar la existencia de

\footnotetext{
${ }^{2}$ Ambos medios de comunicación fueron seleccionados por su cobertura nacional y por la importancia que tienen ambos diarios en la configuración de la opinión pública en Chile. A modo de justificación estadística, es factible indicar que según los datos proporcionados por el Sistema de Verificación de Circulación y
} 
un destinador-codificador; con unas habilidades comunicativas, un nivel de conocimientos, unas actitudes y una relación con el sistema-cultural; el destinatariodecodificador, con sus propias habilidades, conocimientos, actitudes y sistema sociocultural; el mensaje, con un código, un contenido y una forma de presentar figuras constituyentes del discurso mediático donde se representa algo en ausencia del objeto que se advierte; el medio-canal, con unas formas de compulsionar al destinador-codificador y al destinatario-decodificador, unos medios técnicos para la distribución del mensaje, unas limitaciones espacio-temporales, unas preferencias ideológicas y políticas, y unas intenciones. En suma, se advierte un complejo proceso semiótico, donde intervienen variables económicas, políticas e históricas que configuran el marco contextual sobre el que se articulan los discursos.

Así entonces, la problemática investigada ${ }^{5}$ nos ha permitido reflexionar sobre la importancia de comprender que un análisis riguroso del discurso mediático no puede obviar la importancia que tienen las implicancias del contexto y que entendemos como el espacio de significados donde los productores de los discursos en sus diversos tipos interactúan, por lo tanto, es factible evidenciar que en toda cobertura de los variados acontecimientos, el destinador-codificador está condicionado por una serie de factores (medios económicos y tecnológicos disponibles, ideología de la empresa informativa, tiempo disponible, personalidad del individuo, capacitación técnica, nivel de contactos, intencionalidad personal, creencias, actitudes y contexto sociopolítico del momento) que hacen del discurso periodístico un producto informativo que se genera de un complejo proceso donde interactúan los emisores del discurso periodístico, los medios a través de los cuales se difunden las noticias, los posibles efectos y reacciones de los mensajes en las audiencias, y las circunstancias políticas, sociales, económicas y culturales que condicionan la cobertura y tratamiento de los acontecimientos.

Lectoría (2005-2006), en la cual participan la Asociación Nacional de Avisadores (ANDA), la Asociación Chilena de Agencias de Publicidad (Achap) y los principales diarios pagados y gratuitos del país, El Mercurio cuenta con un promedio de 381.125 lectores semanales lo cual aumenta durante los fines de semanas a 491.125. De la misma forma, el diario La Tercera cuenta con un promedio de 303.881 lectores semanales lo cual aumenta durante los fines de semanas a 417.105

${ }^{3}$ Véase diario El Mercurio http://www.elmercurio.cl

${ }^{4}$ Véase diario La Tercera http://www.latercera.cl

${ }^{5}$ Desde una perspectiva teórica-crítica procedente tanto de los estudios del discurso, las representaciones de los mass media y de las nociones actuales sobre el rol de los medios de comunicación en la construcción del Otro, la investigación realizada abordó el estudio de la representación mediática del Perú en los discursos mediáticos que la prensa escrita elaboró a partir del conflicto marítimo del año 2005 entre Chile y Perú. 
Sin embargo, es elemental establecer que en el estudio realizado acerca de la representación mediática del Perú en la prensa chilena ${ }^{6}$, en el caso del conflicto limítrofe entre ambos países, se buscó sólo estudiar la representación propuesta por los medios de comunicación en el marco de la cobertura ${ }^{7}$ de un acontecimiento. Además, esto deja establecido los límites significativos que tiene el estudio y se postula entender el concepto de representación mediática como la capacidad de los medios de comunicación para construir y/o reforzar actitudes, creencias e ideologías sobre la base de una producción de significados que poseen un sustento socio-cognitivo en el conjunto de creencias socialmente compartidas por el colectivo de un país y que en consecuencia, permite a los medios la imposición de una coherencia textual entre proposiciones y discursos a través de los marcos referenciales comunes en complemento con la dimensión contextual que engloba a las prácticas discursivas cotidianas.

Por lo tanto, al asumir que los medios de comunicación poseen la capacidad de proveer a las audiencias de un mensaje informativo que contempla un mapa conceptual capaz de ordenar, clasificar y organizar los hechos y conflictos que involucran a los países, dentro de un contexto histórico referencial apropiado para promover un sentido socialmente aceptado por la mayoría, la investigación centró su problema de estudio en la representación mediática del Perú en el discurso periodístico de los diarios El Mercurio y La Tercera.

En toda investigación la problemática estudiada genera interrogantes cuya finalidad es guiar el desarrollo de la investigación y permitir la formulación de una hipótesis de trabajo. En este caso, el análisis de los discursos elaborados por la prensa chilena como consecuencia del conflicto limítrofe-marítimo ${ }^{8}$ que se gesta a partir de la ley aprobada (3

\footnotetext{
${ }^{6}$ El estudio se concentró en analizar 19 noticias de portada que corresponden al total de discursos periodísticos publicados (desde el viernes 28 de octubre hasta el domingo 6 de noviembre de 2005) por El Mercurio (10 noticias) y La Tercera (9 noticias), durante la cobertura del conflicto limítrofe-marítimo de 2005 entre Chile y Perú.

${ }^{7}$ Véase cuadro resumen (final del texto) de las informaciones publicadas por el diario El Mercurio y La Tercera, sobre el conflicto limítrofe-marítimo de 2005 entre Chile y Perú.

${ }^{8}$ Durante los meses de octubre y noviembre de 2005, los actores que conforman el escenario político latinoamericano y las audiencias fueron testigos de una controversia diplomática entre Chile y Perú. El conflicto entre ambos países tuvo su génesis mediática, a partir del denominado proyecto de ley sobre determinación de las líneas de base de dominio marítimo que fue elaborado por el poder ejecutivo del Perú, presentado el 28 de octubre en el parlamento y, posteriormente, tramitado y aprobado el 3 de noviembre de 2005 por el Congreso del Perú. La ley de líneas de base del dominio marítimo del Perú (No 28.621), que fue aprobada por unanimidad durante el gobierno del Presidente Alejandro Toledo, corresponde a sucesiones de puntos que certifican el lugar exacto donde empieza el mar territorial de un país.

Estas nuevas demarcaciones fronterizas que el Perú aprobó a través de la ley de líneas de base del dominio marítimo, pero que según autoridades del gobierno chileno serían contraproducentes con los límites estipulados en los acuerdos de 1952 (Declaración de Santiago) y 1954 (Convenio sobre Zona Especial
} 
de noviembre de 2005) por el Congreso del Perú para el establecimiento de nuevas líneas de base del dominio marítimo ${ }^{9}$, buscó dar respuesta a la siguiente pregunta: ¿Cuáles son los elementos de significación que subyacen en el discurso periodístico de los diarios El Mercurio y La Tercera, y que sustentan la representación mediática del Perú, a partir de la cobertura y tratamiento mediático del conflicto limítrofe-marítimo de 2005 ?

\section{Nociones teóricas para comprender la lógica del discurso mediático}

Para comenzar este apartado, es necesario establecer que la posición teórica que se plantea en el marco de esta investigación nos permite considerar que el discurso se constituye a partir de un conjunto de enunciados que poseen coherencia en el marco de la dinámica interactiva que llevan a cabo los participantes de la relación discursiva. Por lo demás, el objeto de estudio no puede aislarse del contexto donde se desarrolla, puesto que el discurso es un proceso comunicativo donde los enunciados que se actualizan constantemente permiten que las intencionalidades propuestas por los hablantes se proyecten por medio de estrategias discursivas a modo de lograr la aceptabilidad del contenido propuesto.

A partir de lo anterior, nos remitiremos a lo formulado por Jean Caron (1989: 119120), quien al plantear que el diálogo, como forma natural de ejercicio de la lengua, pone

Fronteriza Marítima) y que fueron ratificados por Perú en el año 1955, por Ecuador en el año 1964 y, finalmente, por Chile en el año 1967, estarían fijadas sobre $37.900 \mathrm{~km}^{2}$ de territorio marítimo chileno.

${ }^{9}$ El presente texto corresponde a los 5 primeros artículos de la Ley № 28.621 que fue tramitado y aprobado el 3 de noviembre de 2005 por el Congreso del Perú.

Artículo 1.- La presente ley establece, en cumplimiento del artículo 54 de la Constitución Política del Perú y de conformidad con el Derecho Internacional, las líneas de base a partir de las cuales se mide la anchura del dominio marítimo del Estado hasta la distancia de doscientas millas marinas, en las que el Estado peruano ejerce soberanía y jurisdicción.

Artículo 2.- Las líneas de base están determinadas por las coordenadas geográficas que constan en el anexo 1, que se inician en el Norte en las coordenadas astronómicas Lat. 0323 33.96S, Long. 8019 16.31W (WGS84 Lat. 0323 31.10S, Long. 8018 49.29W) y finalizan en el Sur en las coordenadas WGS84 Lat. 1821 08S, Long. $702239 \mathrm{~W}$, incluidas en las seis cartas del anexo 2, de la presente ley.

Artículo 3.- De conformidad con el Derecho Internacional, las aguas comprendidas dentro de las líneas de base establecidas en el artículo 1 de la presente Ley, forman parte de las aguas interiores del Estado.

Artículo 4.- De conformidad con la Constitución Política del Estado el límite exterior del dominio marítimo del Perú es trazado de modo que cada punto del citado límite exterior se encuentre a doscientas millas marinas del punto más próximo de las líneas de base en aplicación de los criterios de delimitación establecidos por el Derecho Internacional.

Artículo 5.- El Poder Ejecutivo queda encargado de levantar la cartografía correspondiente al límite exterior del dominio marítimo de conformidad con lo dispuesto en el artículo 4 de la presente ley. 
en el juego discursivo una serie de regulaciones más que estructuras rígidas, propone tres importantes observaciones en torno a la noción de discurso y que se recogen a continuación:

1. En primer lugar el discurso supone una puesta en relación, realizada por la actividad enunciativa, entre un conjunto de enunciados. Sin embargo, no se puede eludir, por una parte, la actualización de los enunciados en el proceso de interacción discursiva y, por otra, la relación de los enunciados que al estar presentes en el discurso remiten a otros enunciados que les dan sentido y determinan la configuración de las funciones a cumplir por el discurso.

2. En segundo lugar el discurso es un proceso, ya que se desarrolla en el tiempo, de forma orientada. En consecuencia, el discurso aparece como una sucesión de transformaciones, que permiten pasar de un estado a otro, luego a otro, y así sucesivamente. Sin duda, la noción de transformación entregada por Caron (1989), pero que podemos encontrar antes en Greimas (1991), permite comprender a los discursos como estructuras interrelacionadas en las que se suceden eventos presentados en forma de programas narrativos $(\mathrm{PN})$.

3. En tercer lugar si se busca comprender el discurso como un conjunto coherente de enunciados, debemos entender que esta sucesión de enunciados que se actualizan por medio de una progresión, está dirigida hacia cierto objetivo. En efecto, como nos sugiere el autor indicado, el discurso es un acto, y como tal, corresponde a una intención, es decir la acción que funda la unidad del discurso. En este sentido, puede y debe pensarse al discurso como puesta en acción.

De este modo, los periodistas y los medios de comunicación tienen la capacidad, por medio de la producción discursiva, de (re)construir, en el plano semiótico del texto, el sentido adscrito a los sucesos insertos en un contexto específico. Esto corresponde, en palabras de J.B Thompson, a la historicidad mediática:

Nuestra percepción del pasado, y nuestra percepción de las maneras en que el pasado afecta a nuestra vida actual, depende cada vez más de una creciente reserva de formas simbólicas mediáticas (Thompson, 1998: 55).

Incluso, los medios de comunicación al generar una telaraña discursiva buscan reafirmar un modelo mental específico que contiene la representación de un objeto, suceso o persona. Pero, lo anterior se transforma en un problema cuando se observa que las intencionalidades de las instituciones mediáticas dominantes apuntan al reforzamiento de un modelo mental positivo sobre "Nosotros" en desmedro de los "Otros" 
construyendo, de este modo, una historia narrativa tensional que reconstruye las lógicas tensionales de la historia referencial.

Así, las variaciones que existen en el plano de la comunicación y que se vinculan directamente con el contexto, logran la actualización y/o adaptación de los contenidos adscritos en los discursos que se configuran con una intencionalidad clara y, por lo demás, los cambios en la situación social, política, económica y cultural de un Estado-nación, gestan cambios en la interpretación de los discursos, lo que - en palabras de Van Dijk favorece al hablante, quien se encarga de identificar, por una parte, el modelo mental del interlocutor y, por otra, el contexto: "Así el hablante tiene un modelo del conocimiento de sus interlocutores o público. Ese modelo del conocimiento controla la información que un(a) hablante incluye en la representación del discurso" (Van Dijk, 2001: 73).

Además, es factible observar que en la situación social donde los medios de comunicación distribuyen noticias, éstos conforman un conjunto o secuencia de enunciados a propósito de un hecho periodístico o acontecimiento noticioso que se desarrolla en un lugar determinado. Pero en el proceso de producción del discurso periodístico, este acontecimiento del cual se habla, sufre modificaciones por medio del proceso de selección, visto este último, como una etapa de la producción que está limitada por los propósitos e intencionalidades existentes en toda actividad comunicativa. Justamente en este sentido puede pensarse al discurso como un juego estratégico y no sólo eso, al discurso mass mediático como una mercancía que se vende, arrienda y, porqué no, contrabandea. Así, los medios, gracias a la labor que ejecutan los elementos integrantes del sistema productivo y a modo de mecanismo de filtración y control informativo, pueden fragmentar una realidad de primer orden y, a continuación, elaborar una realidad de segundo orden, que vendría a visualizarse en la representación construida por los periodistas en el discurso mediático.

Por consiguiente, el discurso en conjunto con la capacidad técnica de los media para distribuir a diversas audiencias un mensaje en forma simultánea, le permite al sujeto miembro de un grupo social experimentar acontecimientos y conocer diversas culturas que en la esfera concerniente a su interacción social jamás podría acceder, por lo tanto, el individuo aprende de los discursos que los medios de comunicación construyen y configuran su conocimiento social desde la lógica instaurada por los productos mediáticos.

Tan profunda es la medida en que nuestra percepción del mundo está configurada por los actuales productos mediáticos que, cuando viajamos a lugares distantes del mundo como visitantes o turistas, nuestras experiencias vividas vienen precedidas, con frecuencia, por grupos de imágenes y expectativas adquiridas a causa de la continua exposición a los productos mediáticos (Thompson, 1998: 56). 
Siguiendo esta lógica, es evidente el cuestionamiento acerca de los tipos de conocimientos que subyacen (o que puedan subyacer) a los esquemas que emplean los periodistas en la elaboración de sus discursos (argumentativos) y cuál es la relación existente entre los hechos que las noticias argumentan e interpretan y el conjunto de conocimientos, valores o ideologías que su autor impregna. Pues bien, los argumentos que los informadores entreguen afectarán en mayor o menor medida, a la opinión pública y con ello, afectará también parte del comportamiento social.

McQuail (1994), al respecto establece que las manifestaciones más visibles y accesibles de la manera en que opera la comunicación de masas es el variado cuerpo de "mensajes" y "significados" que continuamente son trasmitidos por los muchos tipos de empresas mediáticas y recibidos por las audiencias.

La diferencia entre mensaje y significado es importante, puesto que el texto físico del mensaje -letra impresa, sonidos o imágenes- es lo que se puede observar directamente y es, de algún modo, "fijo", mientras que los significados, incorporados en los textos o cuya presencia perciban sus productores o audiencias eventuales, no se pueden observar ni son fijos. Dichos significados son a las vez diversos y a menudo ambiguos (McQuail, 1994: 361).

Según el autor, tanto la teoría como la investigación de los contenidos mediáticos se dividen entre la opción de centrarse en el mensaje o en el significado, ya que frecuentemente se generan, a través de los discursos, generalizaciones referidas a los contenidos de los medios de comunicación de masas, muchos de los cuales pueden conllevar a un contenido tendencioso.

Esta dualidad entre mensaje y significado se vuelve un cuestionamiento importante al momento de enfocarnos en la relación entre los mensajes mediáticos y la realidad que los mismos medios de comunicación social interpretan y que luego representan. "Si bien la cuestión más básica es si los contenidos mediáticos reflejan, o deberían reflejar, la realidad y, si así fuera, ¿qué realidad o la de quién? Esta cuestión, y las eventuales respuestas que se han propuesto, han sido objeto de muchos trabajos teóricos" (McQuail, 1994: 363).

Todo esto construye una incesante incertidumbre en torno a lo que constituye el significado (ya sea de los mensajes como de la realidad construida), dado que en la elaboración periodística existe una gran variedad de tipos de contenidos y cada uno de ellos refleja, de una u otra forma, intenciones de realidad distintas.

Así entonces, se asume que los códigos son sistemas de significados cuyas reglas y convenciones comparten los miembros de una cultura, también denominada comunidad interpretativa. De esta forma, estos códigos contribuirán a crear vínculos entre los periodistas y las audiencias, a las cuales proporcionan las bases de la interpretación. Todo esto nos permite comprender el mundo mediante el conocimiento de códigos y 
convenciones interpretativas (McQuail, 1994), lo que asegura el proceso de decodificación de los contenidos presentados en el texto y en esta medida el texto se convierte en un espacio coherente de interacción textual (Abril, et al., 2004).

Ahora bien, al comprender que el discurso mediático es una elaboración social que se transforma en nexo y puente entre la labor informativa y la sociedad, es factible sostener desde la perspectiva planteada por Van Dijk (2000) - que a partir de esta relación surgen factores sociales que se encuentran presentes en el discurso. El discurso, por tanto, se transforma en un proceso de interacción comunicativa y en un nivel mayor en un proceso de interacción social.

Por consiguiente, el discurso es definido como acción y, por lo tanto, éste siempre se elabora dentro de un contexto, entendiéndolo como la interfaze entre discurso (como acción) y las estructuras sociales. "El discurso se produce, comprende y analiza en relación con las características del contexto. Por lo tanto, se interpreta que el análisis social del discurso define texto y habla como situados: describe el discurso como algo que ocurre o se realiza en una situación social” (Van Dijk, 2000: 32).

Intrínsicamente al discurso se vincula también el poder y las ideologías con el propósito de lograr influir sobre los intereses sociales y alcanzar cierto dominio sobre ellos para la propia reproducción de las ideologías al interior de la sociedad.

El discurso nace en una situación social, dentro de la cual los individuos son elementos cruciales así como también sus roles de acción (entre los cuales podemos diferenciar, por ejemplo, a los destinatarios y receptores).

Por su parte, los medios de comunicación social como empresas informativas, poseen una ideología determinada, conocida también como línea editorial (que si bien viene al caso considerar, para efectos de esta investigación no ahondaremos mayormente al respecto), que por supuesto los informadores que trabajan en estos soportes mediáticos deben compartir. De esta forma "habrá consenso acerca de lo que es interesante, lo que es noticia y cómo deben ser tratados los distintos temas" (Van Dijk, 1990: 45).

Es decir, los mass media al controlar la difusión de los diversos discursos públicos que a diario elabora y difunde, también ejercen un control directo sobre el contexto al tener el poder de decretar qué será noticia, el tratamiento que amerita la información y cómo se dará a conocer. Esto permite anticipar que los diarios de agentes dominantes escribirán cómo escriben los agentes dominantes y sobre lo qué deben escribir/leer los agentes dominantes, produciendo un orden de hegemonía y muchas veces, de perpetuación de estereotipos.

"Los poderosos son entonces capaces no sólo de controlar sucesos comunicativos, sino también de definir el orden del día." (Van Dijk, 1990: 47). Al respecto, el autor agrega que si los receptores no tienen información alternativa a lo que un determinado medio de comunicación difunde, no tendrán acceso a otros discursos y por ende, la credibilidad de 
los respectivos discursos puede generar un efecto persuasivo, ya que serán los mismos receptores quienes adoptarán tales creencias y posturas aunque se trate de un discurso prejuicioso.

En consecuencia, podemos afirmar que a través del discurso es posible establecer una representación de la realidad, y que en definitiva es allí donde radica la importancia y el significado de la noticia como discurso social.

\section{Diseño metodológico}

El análisis complejo del discurso que se utilizó para desarrollar la investigación fue construido sobre la base de las perspectivas teóricas trabajadas por J. Courtés (1995), J -C. Giroud y L. Panier (1988), en el marco del análisis semiótico textual, y por medio de las ideas de J. Potter (1998), quien propone identificar las representaciones discursivas a partir de las factualidades reconocibles en todo texto; las cuales han sido re-elaboradas desde la perspectiva teórico-metodológica trabajada por Del Valle (2006).

De esta forma, en la investigación se aplicó un análisis complejo del discurso que nos permitió estudiar los textos que la prensa publicó a partir de la cobertura del conflicto entre dos Estado-nación (Chile y Perú).

Por lo tanto, 19 noticias de portada corresponden al total de discursos periodísticos publicados por El Mercurio (10 noticias) y La Tercera ( 9 noticias), durante la cobertura del conflicto limítrofe-marítimo de 2005 entre Chile y Perú. Las noticias publicadas en portada entre el viernes 28 de octubre y el domingo 6 de noviembre de 2005, fueron seleccionadas de acuerdo a los siguientes criterios.

Tabla 1. Criterios de la muestra

\begin{tabular}{|l|l|}
\hline a) Género & Informativo y/o Interpretativo \\
\hline b) Sección & Portada \\
\hline c) Periodos & Octubre y Noviembre de 2005 \\
\hline d) Temporalidad & $\begin{array}{l}\text { Noticias publicadas a partir del 28 de } \\
\text { octubre al 6 de noviembre de 2005. }\end{array}$ \\
\hline e) Tópicos o Temas & $\begin{array}{l}\text { Conflicto limitrofe-marítimo entre Chile y } \\
\text { Perú que se gesta a partir de la ley } \\
\text { aprobada por el Congreso del Perú para el } \\
\text { establecimiento de nuevas lineas de base } \\
\text { del dominio marítimo. }\end{array}$ \\
\hline f) Participantes o Actores & $\begin{array}{l}\text { Presidente de Perú, Presidente de Chile, } \\
\text { Ministros de Relaciones Exteriores de } \\
\text { ambos pares, } \\
\text { Congresistas, Ministro Secretario General } \\
\text { del Gobierno de Chile, Ministro de Defensa } \\
\text { de Chile, }\end{array}$ \\
\hline
\end{tabular}


Cabe destacar entonces que la investigación analizó un corpus extraído de los diarios El Mercurio y La Tercera. Ambos medios de comunicación fueron seleccionados por su cobertura nacional y por tener - en el primer caso - la mayor circulación en nuestro país y - en el segundo caso - por tener el cuarto lugar en el promedio de circulación en comparación con otros diarios existentes en Chile. Sin embargo, lo anterior se complementa con la importancia que tienen ambos diarios en la configuración de la opinión pública en Chile y los niveles de lectoría que ostenta cada producto informativo.

Por consiguiente, a modo de justificación estadística, es factible indicar que según los datos proporcionados por el Sistema de Verificación de Circulación y Lectoría (20052006), en la cual participan la Asociación Nacional de Avisadores (ANDA), la Asociación Chilena de Agencias de Publicidad (Achap) y los principales diarios pagados y gratuitos del país, El Mercurio cuenta con un promedio de 381.125 lectores semanales lo cual aumenta durante los fines de semanas a 491.125. De la misma forma, el diario La Tercera cuenta con un promedio de 303.881 lectores semanales lo cual aumenta durante los fines de semanas a 417.105 .

\subsection{Modelo de análisis complejo del discurso}

El modelo de análisis complejo del discurso utilizado en el estudio de la representación mediática, procura descubrir, revelar o divulgar conexiones que a menudo se encuentran implícitas en los discursos y, en consecuencia, el modelo trabaja sobre manifestaciones explícitas e implícitas existentes en los textos, como es el caso de los actores, roles, lugares simbólicos, valores temáticos, situaciones discursivas, fabricación de consensos, recorridos figurativos, lógicas de poder y matrices ideológicas.

Tabla 2. Criterios de análisis

\begin{tabular}{|l|l|}
\hline \multicolumn{2}{|l|}{ DIMENSIÓN DISCURSIVA } \\
\hline FIGURAS & $\begin{array}{l}\text { Las figuras son elementos de significación más o menos } \\
\text { determinados, pero reconocibles en la lectura. Se dividen en } \\
\text { actores, tiempo y lugares. }\end{array}$ \\
\hline $\begin{array}{l}\text { RECORRIDOS } \\
\text { FIGURATIVOS }\end{array}$ & $\begin{array}{l}\text { Las figuras están dispuestas en recorridos figurativos. Esto se } \\
\text { debe entender como el modo en que el texto utiliza las figuras } \\
\text { y la manera como se desarrolla una figura en el texto. }\end{array}$ \\
\hline VALORES TEMÁTICOS & $\begin{array}{l}\text { Es el sentido que se construye a partir de las relaciones entre } \\
\text { las figuras y sus recorridos figurativos. Por lo tanto, las figuras } \\
\text { tienen un valor a partir de su relación con otras figuras. Es la } \\
\text { especificidad de las figuras, es decir, el papel que cumple cada }\end{array}$ \\
\hline
\end{tabular}




\begin{tabular}{|c|c|c|c|}
\hline & \multicolumn{3}{|l|}{ una en el texto. } \\
\hline SITUACIONES DISCUSIVAS & \multicolumn{3}{|c|}{$\begin{array}{l}\text { Todo texto dispone a los actores en un(os) tiempo(s) y en un } \\
\text { (os) lugar(es), permitiendo esta disposición la lectura de un } \\
\text { texto a partir de la identificación de situaciones discursivas } \\
\text { (relaciones entre figuras). }\end{array}$} \\
\hline \multicolumn{4}{|l|}{ DIMENSIÓN FACTUAL } \\
\hline DISCURSO EMPIRISTA & \multirow{2}{*}{\multicolumn{3}{|c|}{$\begin{array}{l}\text { "... no se limita a centrarse en los datos sino que los construye } \\
\text { como si tuvieran una agencia propia" (Potter, 1998: 152). } \\
\text { "... los participantes tienden a construir corroboración } \\
\text { cuando elaboran y socavan relatos [pues] los procedimientos } \\
\text { para la construcción de hechos no trabajan de manera aislada. } \\
\text { Tienen la misma probabilidad de que se recurra a ellos } \\
\text { conjuntamente" (Potter, 1998: 152-153). }\end{array}$}} \\
\hline $\begin{array}{l}\text { FABRICACIÓN DEL } \\
\text { CONSENSO }\end{array}$ & & & \\
\hline $\begin{array}{l}\text { DETALLES EN LA } \\
\text { NARRACIÓN }\end{array}$ & \multicolumn{3}{|c|}{$\begin{array}{l}\text { "los datos específicos de una descripción, son cruciales para la } \\
\text { actividad a la que se destina la descripción [y] son } \\
\text { descripciones detalladas con minuciosidad" (Potter, 1998: } \\
\text { 154). }\end{array}$} \\
\hline $\begin{array}{l}\text { MAXIMIZACIÓN / } \\
\text { MINIMIZACIÓN }\end{array}$ & \multicolumn{3}{|c|}{$\begin{array}{l}\text { “la formulación de 'casos extremos' [y] que consiste en } \\
\text { utilizar los extremos de las dimensiones descriptivas } \\
\text { pertinentes" (Potter, 1998: 238). }\end{array}$} \\
\hline $\begin{array}{l}\text { NORMALIZACIÓN / } \\
\text { ANORMALIZACIÓN }\end{array}$ & \multicolumn{3}{|c|}{$\begin{array}{l}\text { “... describir una acción que, por consenso, se considera } \\
\text { anormal o extraña [utilizando] una organización discursiva } \\
\text { que describe una actividad y que, al mismo tiempo, } \\
\text { proporciona pistas para verla como anormal o extraña [por lo } \\
\text { cual] la cuestión de la anormalidad está estrechamente } \\
\text { vinculada con la cuestión de la regularidad" (Potter, 1998: } \\
247-248 \text { ). }\end{array}$} \\
\hline \multicolumn{4}{|l|}{$\begin{array}{l}\text { DIMENSIÓN SEMIÓTICA } \\
\text { (CUADRADO SEMIÓTICO) }\end{array}$} \\
\hline $\begin{array}{l}\text { RELACIONES DE } \\
\text { CONTRARIEDAD }\end{array}$ & \multicolumn{3}{|c|}{ Relación lógica entre $\mathrm{A}$ y $\mathrm{B}$, y entre $\mathrm{NO} \mathrm{B}$ y NO A. } \\
\hline $\begin{array}{l}\text { RELACIONES DE } \\
\text { CONTRADICCIÓN }\end{array}$ & \multicolumn{3}{|c|}{ Relación lógica entre $\mathrm{A}$ y NO A, y entre $\mathrm{B}$ y NO B. } \\
\hline $\begin{array}{l}\text { RELACIONES DE } \\
\text { COMPLEMENTARIEDAD }\end{array}$ & \multicolumn{3}{|c|}{ Relación lógica entre A y NO B, y B y NO A. } \\
\hline A & NOA & B & NOB \\
\hline $\begin{array}{l}\text { Representación lógica del } \\
\text { SER. }\end{array}$ & $\begin{array}{l}\text { Representación } \\
\text { lógica del NO } \\
\text { SER. }\end{array}$ & $\begin{array}{l}\text { Representación } \\
\text { lógica del } \\
\text { PARECER. }\end{array}$ & $\begin{array}{l}\text { Representación } \\
\text { lógica del NO } \\
\text { PARECER. }\end{array}$ \\
\hline
\end{tabular}




\section{RESULTADOS}

Cabe destacar, que la dimensión histórica que une a Chile y Perú corresponde a una lógica (Memoria - Conflicto $)^{10}$ que cobra significación en el discurso de la prensa chilena. Esta relación entre memoria y conflicto - a modo de ejemplo - se hizo explícita cuando un parlamentario peruano (Gustavo Pacheco ${ }^{11}$ ) es citado por la prensa nacional (Chile) en el momento que recuerda durante la sesión del Congreso que tenía como objetivo la aprobación de la Ley de Líneas de Base, a aquellos marinos que entregaron y perdieron su vida en el Pacífico defendiendo la causa peruana.

Indudablemente, el discurso de esta figura actor motiva a los medios de comunicación chilenos para publicar informaciones que aumentan la tensión en el marco del conflicto entre Chile y Perú. Además, con el uso de la mencionada cita, el discurso mediático chileno entrega una imagen del sentimiento nacionalista que existe en el Congreso peruano como en todo el país, ad portas de ser aprobada la Ley de Líneas de Base, situación que marca el clímax de este impasse diplomático.

Asimismo, en la prensa ${ }^{12}$ se muestra como el parlamentario resalta la figura de Miguel Grau y alude a la imagen y recuerdo de Arturo Prat como el principal enemigo del héroe peruano y, por lo mismo, lo utiliza como un elemento simbólico que fortalece el actual reclamo marítimo por parte de la administración de Toledo, reclamo, por lo demás, que se ha convertido en un tema político de envergadura internacional (Tribunal de La Haya ${ }^{13}$ ).

A su vez, la figura actor de la administración de Toledo, sitúa a Chile en una posición de enemistad y conflicto, por cuanto el verdadero origen del actual conflicto marítimo, tendría su génesis en la conducta chilena dentro del marco de la Guerra del Pacífico. Esto nos remite a pensar la historia como espacio de conflicto actualizado en los discursos.

Por otra parte, al igual que la imagen proyectada por el Presidente Toledo, Ricardo Lagos, en la prensa ${ }^{14}$ de Chile representa a un político y autoridad que cuenta con el apoyo y respaldo absoluto, tanto por parte de las autoridades que componen su administración, así también como por parte de la opinión pública nacional. De esta forma, asume un rol de estratega, autoridad, inteligencia y prudencia.

\footnotetext{
${ }^{10}$ Véase edición del diario El Mercurio (30/10/08)

${ }^{11}$ Abogado y ex parlamentario del Perú. A su vez, durante la sesión (3 de noviembre de 2005) del parlamento limeño que aprobó la Ley de Líneas de Base, Gustavo Pacheco era el presidente del Comité de Relaciones Exteriores del Congreso.

${ }^{12}$ Véase edición del diario La Tercera $(4 / 11 / 2005)$

${ }^{13}$ En el actual marco del conflicto limítrofe, presentado por Perú en el mes de marzo de 2008 ante la Corte Internacional de La Haya, se observa la misma convergencia del espectro social-político chileno, está vez aglutinado bajo la administración de la presidenta Michelle Bachelet.

${ }^{14}$ Véase ediciones de los diarios El Mercurio y la Tercera $(03 / 11 / 08)$
} 
Dicho de otra forma, el impasse marítimo es aprovechado por los mandatarios como un escenario en el cual han podido desplegar sus habilidades políticas, incrementar su popularidad dentro de sus respectivos países, así como también para activar sus contactos diplomáticos dentro de Latinoamérica. En este sentido se entiende la visita diplomática del presidente ecuatoriano en el mes de marzo de 2008 y donde este mandatario entrega su apoyo a Chile.

Cabe agregar que dicho impasse diplomático, centrado en la ley peruana que busca un reordenamiento de los límites marítimos con Chile, no sólo perjudica las relaciones entre Chile y Perú, sino que también, aumenta el grado de tensión, hostilidad, preocupación e inestabilidad dentro de América del Sur. Por ende, en el discurso mediático de la prensa ${ }^{15}$ chilena se alude a la importancia que tienen los mandatarios de los países latinoamericanos. Este conjunto de Estados-nación tienen un valor de compromiso, apoyo y respaldo, por cuanto se manifiestan atentos y preocupados frente al impasse diplomático que sostiene Chile y Perú.

Asimismo, los dos países en conflictos, consideran estas administraciones regionales como piezas clave para lograr una resolución del impasse, ya que dentro de la ofensiva diplomática impulsada por ambos, atribuyen a éstos la importancia de mantenerlos informados respectos a sus posturas frente al tema limítrofe.

De esta forma, dentro del discurso surgen los países de Ecuador, Bolivia, Brasil, Gran Bretaña y Estados Unidos, como actores que a raíz de los recorridos figurativos establecidos por Chile y Perú, se ven involucrados dentro del desarrollo del impasse, teniendo que asumir posiciones favorables para uno y desfavorables para otro.

No obstante, según lo analizado, podemos apreciar que los gobiernos latinoamericanos tienen un rol políticamente correcto, ya que aún cuando aceptan tomar participación a través de reuniones bilaterales con las autoridades y delegaciones chilenas y peruanas, no asumen una posición crítica ni arbitraria que nos haga entender que apoyan a un gobierno más que a otro.

Por otro lado, de los gobiernos regionales citados dentro del discurso ${ }^{16}$, podemos establecer que Ecuador y Bolivia marcan una diferencia respecto a los demás países, ya que en el primer caso, corresponde a un país que también suscribió los tratados limítrofes que definen la delimitación entre Chile y Perú. Por su parte, Bolivia dentro del discurso adquiere un rol prominente y se convierte, por lo mismo, en un elemento que marca un punto de inflexión en el marco del conflicto, puesto que su posición, sumada a la chilena, significarán para la causa peruana una gran barrera diplomática que, por lo demás, reafirma que el impasse suscitado en Lima ha logrado desestabilizar a más de un gobierno y ha logrado quebrantar la armonía regional.

\footnotetext{
${ }^{15}$ Véase edición del diario El Mercurio (3/11/2005)

${ }^{16}$ Véase edición del diario La Tercera (30/10/2005)
} 
Bolivia $^{17}$, surge dentro del discurso como un actor que representa preocupación y análisis, ya que comprende que si desea concretar finalmente la posibilidad de tener acceso a una zona marítima, deberá apoyar a una de las dos causas y, en vista de los análisis que realiza respecto de las consecuencias que implica la Ley de Líneas de Base, adopta un discurso de cautela, pero con la certeza de rechazar y oponerse ante cualquier situación que atente contra sus objetivos históricos.

Entonces, es factible asumir que los conceptos de tensión, conflicto, ilegalidad y arbitrariedad hacen referencia al clima que rodea las relaciones diplomáticas entre ambos países y, de la misma forma, refleja la posición de análisis y crítica asumida dentro del discurso, por el gobierno del Presidente Ricardo Lagos.

Es por ello que según las declaraciones ${ }^{18}$ del Mandatario chileno, Perú mantendría un doble discurso en las relaciones diplomáticas que sostiene, por un lado, con Chile y, por otro, con Ecuador, por cuanto establece que no existen temas pendientes limítrofes con el gobierno ecuatoriano, pero sí con el gobierno de Ricardo Lagos, en instancias que el

\footnotetext{
${ }^{17}$ Desde la lógica de análisis planteada por la dimensión factual, podemos observar lo siguiente en el marco del análisis discursivo.
}

\section{DISCURSO EMPIRISTA}

Los datos empíricos utilizados en el discurso mediático se vinculan con la mención a las aspiraciones históricas de Bolivia y las consecuencias negativas que tiene la acción peruana para los intereses del país altiplánico.

\section{FABRICACION DEL CONSENSO}

En el discurso se vuelve a observar una ausencia de fuentes directas vinculadas a la postura peruana y aparecen fuentes vinculadas con la posición boliviana, por lo tanto las declaraciones de las autoridades chilenas refuerzan la negativa imagen consensuada en torno al gobierno peruano y su conflictiva actitud frente al tema marítimo.

\section{DETALLES EN LANARRACIÓN}

En el discurso no se presenta una descripción detallada sobre el problema de las aspiraciones bolivianas, sino más bien se informa acerca de las consecuencias de la crisis y se integra a un nuevo actor en el conflicto limítrofe entre Chile y Perú.

\section{MAXIMIZACIÓN / MINIMIZACIÓN}

Se acentúa la imagen negativa del gobierno peruano, a partir de los efectos que acarrea su decisión política de modificar los límites marítimos. De esta manera, el ingreso de un nuevo actor al conflicto permite al gobierno de Chile reforzar su imagen de conciliador.

\section{NORMALIZACIÓN / ANORMALIZACIÓN}

En el discurso mediático, se evidencia como la figura de Perú se asocia a una Estado-nación conflictivo que perjudica - además de Chile - a otros Estado-nación como es el caso de Bolivia. Por consiguiente, su actitud se vincula a una acción discursiva de anormalidad frente al accionar diplomático de Chile en el marco del conflicto.

${ }^{18}$ Véase edición del diario La Tercera $(04 / 11 / 2005)$ 
acuerdo de delimitación marítima suscritos entre estos tres países rige de igual manera en ambos casos.

Un resumen de las relaciones y principales conceptos que se encontraron en esta investigación es el siguiente:

Figura 1. Resumen de relaciones semióticas (elaboración propia)

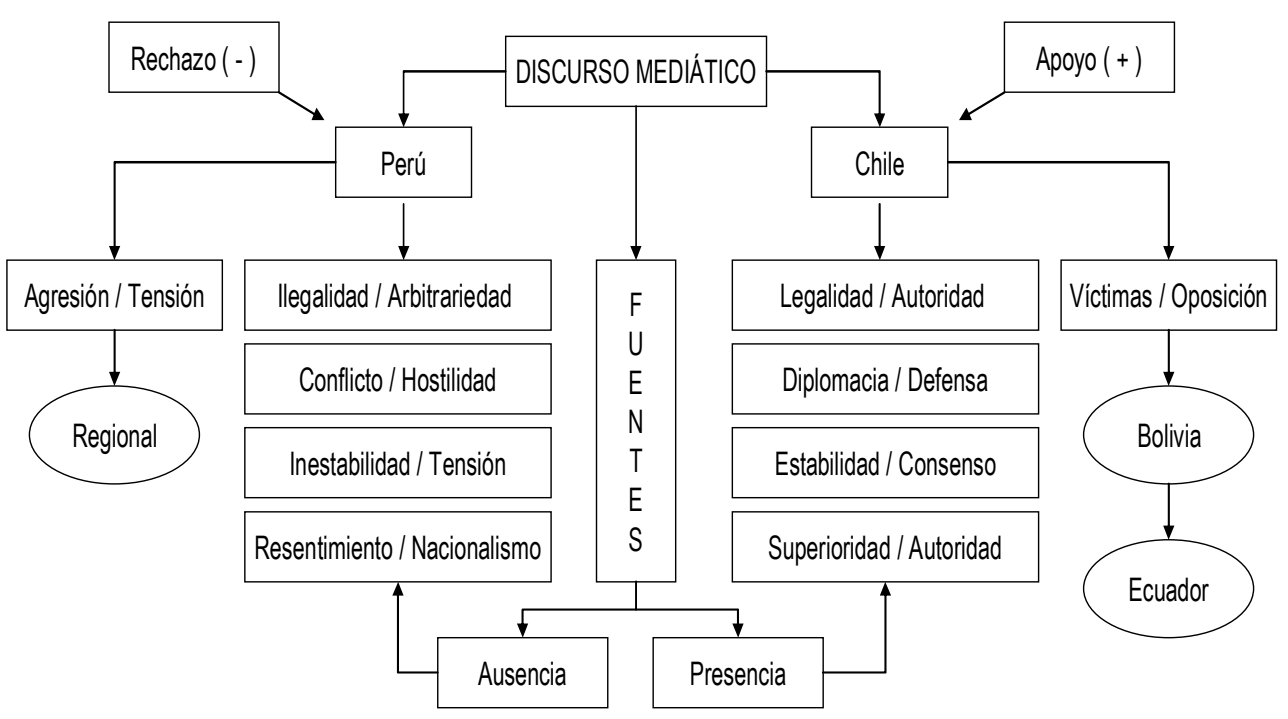

Por último, dentro del discurso mediático la ausencia de fuentes directas vinculadas a la postura peruana, permite que las declaraciones de las autoridades chilenas refuercen la representación consensuada acerca de la imagen negativa ${ }^{19}$ que existe en el colectivo social chileno acerca del gobierno del Perú. Por lo tanto, en el discurso de la prensa nacional, la postura de Chile se configura a partir de los conceptos de cautela, estrategia, análisis, fuerza política y legalidad. Frente al sentido que se adscribe a la posición peruana, la cual se estructura sobre la base de una acción política sin fundamentos legales que busca desviar las críticas realizadas por la ciudadanía al gobierno de Toledo. De este modo, se construye una representación del otro como un sujeto inestable que busca desequilibrar la armonía regional.

\footnotetext{
${ }^{19}$ Véase resultados de las encuestas realizadas por el Centro de Estudios de la Realidad Contemporánea (CERC). Encuesta de octubre de 2006 y abril de 2007.
} 


\section{Consideraciones finales}

Sin duda que los diversos discursos producidos por los medios de comunicación en el marco de las relaciones internacionales entre los gobiernos de Perú y Chile han desencadenado una serie de acciones sociales que se enmarcan dentro del sistema político, económico y social de ambas naciones. Así, los discursos mediáticos y políticos que corresponden al Estado de Chile y que son producidos por las autoridades tanto de gobierno como de oposición, se pueden clasificar como un mecanismo estratégico que busca perpetuar el sentido común en torno a la presencia "amenazante" del Otro y, de esta manera, fortalecer el poder de las clases dominantes por medio de la configuración tautológica y permanente de las visiones sobre la realidad.

A su vez, debemos tener absoluta claridad que el discurso mediático que se genera a partir de las relaciones internacionales no está únicamente constituido por un conjunto determinado de proposiciones que se sustentan en abstracciones complejas de sentido sino que, además, éste se conforma a partir de una secuencia - a modo de efecto dominó de acciones políticas en el marco de la interacción discursiva generada tanto por el sujeto como por el colectivo de ambos países.

Figura 2. Dinámicamediática de construcción significativa

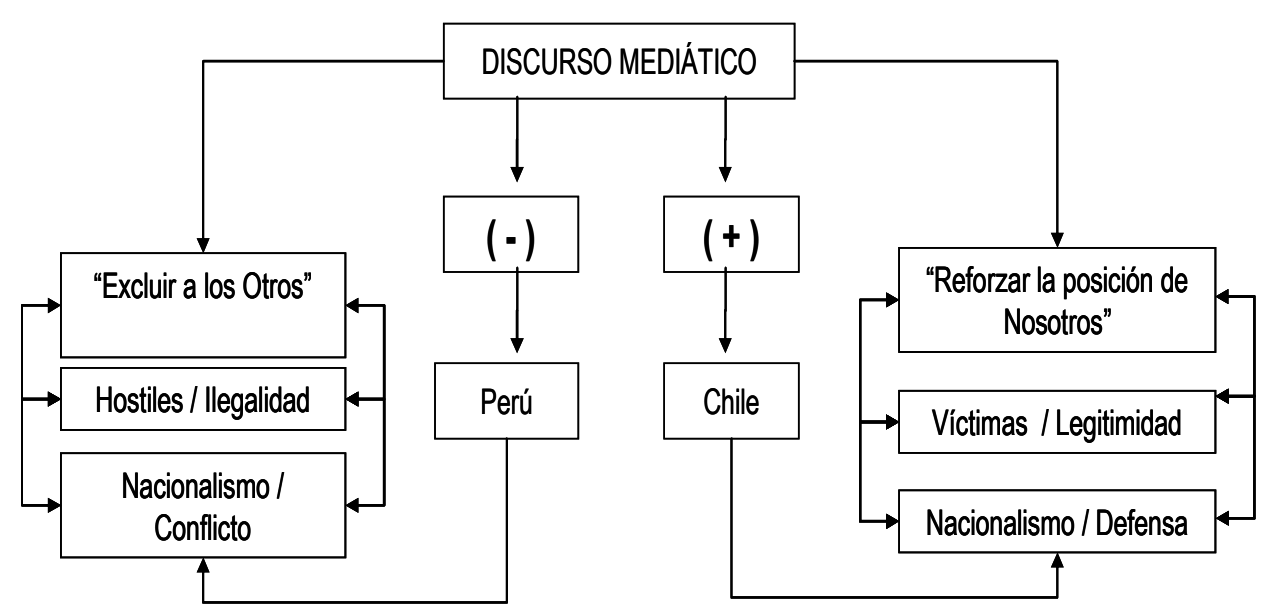

Lo anterior, nos permite aventurarnos - desde una perspectiva crítica - a enarbolar una idea que alude a que en el marco de las relaciones discursivas, la representación del mundo, particularmente del Perú, ha sido construida sobre la base de elementos de significación discriminatorios que producen una representación textual de intolerancia acerca del Otro que es vinculado con implicaciones de carácter negativo para el desarrollo 
del país y donde las manifestaciones políticas y mediáticas de diversa índole, llevadas a cabo por un sujeto o colectivo que representa a la nación peruana, se clasifican como acciones que atentan contra el orden socioeconómico y político establecido para el bienestar del pueblo chileno.

De este modo, las representaciones que se configuran tanto en el discurso político y mediático chileno, gestan un sistema ordenado de referencia dominante que pretende otorgar un sentido homogéneo al mundo social como mecanismo utilizado para mantener categorías históricas acerca del Otro. Por lo tanto, la acción discursiva de los mass media tiende a producir una simplificación sígnica de un Estado-nación por medio de la producción de esquemas interpretativos capaces de facilitar al colectivo dominante la distinción entre el Nosotros y los Otros.

Ahora, las representaciones sustentadas en un principio ideológico que logra modificar el discurso político y mediático, tienen la facultad de categorizar al colectivo exógeno ${ }^{20}$ sobre la base de creencias compartidas socioculturalmente en los grupos dominantes $y$, de esta manera, se pretende establecer un discurso verosímil capaz de reforzar en la memoria histórica las imágenes que se han transmitido por medio de las diversas operaciones socializadoras de cada sociedad.

Para Manuel Martín Serrano - en el contexto de las visiones que pueden llegar a producir los diversos aparatos ideológicos - las representaciones que se configuran sobre la realidad, "ofrecen un modelo del mundo reconocible en el entorno o tácticamente posible; sugiere a los Actores comportamientos factibles y aceptados; y describen situaciones que suelen ser las más probables" (Martín Serrano, 1986: 44).

De esta manera, la condición ideológica de los medios de comunicación determina la configuración de un objeto duplicado in absentia del objeto real y se establece una mímesis sobre la base de la presencia (simulación) de algunas propiedades del objeto representado, construyendo la denominada confusión y construcción de simulacros de la cual habla Jean Baudrillard (1990), refiriéndose a la función desempeñada por los medios en la sociedad actual.

A partir de lo descrito, se puede observar que los medios de comunicación elaboran discursos donde los significados que se adscriben a los acontecimientos del presente, siempre están alineados - en la medida que sea favorable a los objetivos propuestos por el enunciador - a las representaciones del pasado y, por ende, la producción de significados apunta a la correlación entre las imágenes propuestas por la dimensión histórica y las representaciones producidas por las instituciones que controlan las múltiples instancias de socialización a partir de las lógicas de poder imperante en el mundo actual. En caso contrario, los mass media generan discursos conformados por una matriz de significados

\footnotetext{
${ }^{20}$ Concepto utilizado en la investigación para describir a todo Estado-nación o grupo de individuos que no son parte del colectivo dominante (en este caso Chile).
} 
nuevos que se contraponen a las representaciones del pasado y, en consecuencia, los nuevos relatos pretenden institucionalizar una determinada interpretación de lo que acontece.

\section{Referencias bibliográficas}

Abril, Gonzalo, Peña-Marín, Cristina y Lozano, Jorge. 2004. Hacía una semiótica de la interacción textual. Madrid. Cátedra.

Baudrillard, Jean. 1990. Cultura y simulacro. Barcelona. Kayros

Caron, Jean. 1989. Las regulaciones del discurso. Madrid. Gredos.

Courtés, Joseph. 1995. Análisis semiótico del discurso. Del enunciado a la enunciación. Madrid. Gredos.

Del Valle Rojas, Carlos. 2006. Comunicación participativa, Estado-nación y democracia. Discurso, tecnología y poder. Temuco. Ediciones Universidad de la Frontera.

Giroud, Jean-Claude y Panier, Louis. 1988. Semiótica. Navarra. Verbo Divino.

Greimas, Aljirdes y Courtes Joseph. 1991. Diccionarios razonado de Semiótica. Vol 2. Madrid. Gredos.

Martín Serrano, Manuel. 1986. La producción social de comunicación. Madrid. Alianza.

McQuail, Dennis. 1994. Introducción a la Teoría de la Comunicación de Masas (3a ed.). Barcelona. Editorial Paidós Ibérica.

Potter, Jonathan. 1998. La representación de la realidad. Discurso, retórica y construcción social. Barcelona. Paidós.

Thompson, John .B. 1998. Los media y la modernidad. Una teoría de los medios de comunicación. Barcelona. Paidós.

Van Dijk, Teun. A. 1990. La noticia como discurso. Comprensión, estructura y producción de la información ( $1^{\mathrm{a}} \mathrm{ed}$.). Barcelona. Paidós Comunicación.

Van Dijk, Teun. A. 2000. El discurso como interacción social. Estudios del discurso: introducción interdisciplinaria ( $1^{a}$ ed.). Barcelona. Editorial Gedisa S.A

Van Dijk, Teun. A. 2001. Algunos principios de una teoría del contexto. Revista Latinoamericana de Estudios del Discurso (ALED).pp. 69-81. 


\section{ANEXO}

Cuadro resumen de las informaciones publicadas por el diario El Mercurio y La Tercera, sobre el conflicto limítrofe-marítimo de 2005 entre Chile y Perú.

\begin{tabular}{|c|c|c|c|}
\hline $\begin{array}{l}\text { Identificación del Medio de } \\
\text { Comunicación }\end{array}$ & $\begin{array}{l}\text { Titular de la información } \\
\text { periodística. }\end{array}$ & $\begin{array}{l}\text { Fecha de } \\
\text { publicación }\end{array}$ & Sección \\
\hline El Mercurio & $\begin{array}{l}\text { "Perú prepara ley que redefine límite } \\
\text { marítimo" }\end{array}$ & $\begin{array}{l}\text { viernes } 28 \text { de octubre } \\
\text { de } 2005\end{array}$ & Portada \\
\hline El Mercurio & $\begin{array}{l}\text { "Gobierno estima delicada situación creada } \\
\text { por Peru" }\end{array}$ & $\begin{array}{l}\text { sábado } 29 \text { de octubre } \\
\text { de } 2005\end{array}$ & Portada \\
\hline La Tercera & $\begin{array}{l}\text { "Gobierno califica como delicado intento de } \\
\text { Perú por cambiar límite marítimo" }\end{array}$ & $\begin{array}{l}\text { sábado } 29 \text { de octubre } \\
\text { de } 2005\end{array}$ & Portada \\
\hline El Mercurio & $\begin{array}{l}\text { "Perú desconoce tratados y pide negociar los } \\
\text { límites marítimos" }\end{array}$ & $\begin{array}{l}\text { domingo } 30 \text { de } \\
\text { octubre de } 2005\end{array}$ & Portada \\
\hline La Tercera & $\begin{array}{l}\text { "Limite maritimo: dura respuesta de Perú y } \\
\text { Chile lanza ofensiva regional" }\end{array}$ & $\begin{array}{l}\text { domingo } 30 \text { de } \\
\text { octubre de } 2005\end{array}$ & Portada \\
\hline El Mercurio & $\begin{array}{l}\text { "Documentos peruanos dan la razón a } \\
\text { Chile" }\end{array}$ & $\begin{array}{l}\text { lunes } 31 \text { de octubre } \\
\text { de } 2005\end{array}$ & Portada \\
\hline La Tercera & $\begin{array}{l}\text { "Gobierno suaviza discurso y refuerza } \\
\text { ofensiva diplomática por límite marítimo" }\end{array}$ & $\begin{array}{l}\text { lunes } 31 \text { de octubre } \\
\text { de } 2005\end{array}$ & Portada \\
\hline El Mercurio & "Chile defiende con firmeza límite marino" & $\begin{array}{l}\text { martes } 1 \text { de } \\
\text { noviembre de } 2005\end{array}$ & Portada \\
\hline La Tercera & $\begin{array}{l}\text { "Lagos refuerza ofensiva politica y } \\
\text { comunicacional ante impasse con Perú" }\end{array}$ & $\begin{array}{l}\text { martes } 1 \text { de } \\
\text { noviembre de } 2005\end{array}$ & Portada \\
\hline El Mercurio & "Perú ofrece verificar límite de nueva ley" & $\begin{array}{l}\text { miércoles } 2 \text { de } \\
\text { noviembre de } 2005\end{array}$ & Portada \\
\hline La Tercera & $\begin{array}{l}\text { "Perú envía dura nota de protesta contra } \\
\text { Chile e inicia ofensiva diplomática" }\end{array}$ & $\begin{array}{l}\text { miércoles } 2 \text { de } \\
\text { noviembre de } 2005\end{array}$ & Portada \\
\hline El Mercurio & $\begin{array}{l}\text { "Fuerte advertencia de Lagos: Chile ejercerá } \\
\text { su soberanía en el mar" }\end{array}$ & $\begin{array}{l}\text { jueves } 3 \text { de noviembre } \\
\text { de } 2005\end{array}$ & Portada \\
\hline La Tercera & $\begin{array}{l}\text { "Chile advierte a Perú por inminente } \\
\text { aprobación de ley sobre límite marítimo" }\end{array}$ & $\begin{array}{l}\text { jueves } 3 \text { de noviembre } \\
\text { de } 2005\end{array}$ & Portada \\
\hline El Mercurio & $\begin{array}{l}\text { "Lagos inicia ofensiva diplomática personal } \\
\text { por situación con Peru" }\end{array}$ & $\begin{array}{l}\text { viernes } 4 \text { de } \\
\text { noviembre de } 2005\end{array}$ & Portada \\
\hline La Tercera & $\begin{array}{l}\text { "Congreso peruano aprueba ley de territorio } \\
\text { marítimo y Chile rechaza su validez" }\end{array}$ & $\begin{array}{l}\text { viernes } 4 \text { de } \\
\text { noviembre de } 2005\end{array}$ & Portada \\
\hline El Mercurio & $\begin{array}{l}\text { "Chile suspende ronda para negociar } \\
\text { acuerdo comercial con Perú" }\end{array}$ & $\begin{array}{l}\text { sábado } 5 \text { de } \\
\text { noviembre de } 2005\end{array}$ & Portada \\
\hline
\end{tabular}




\begin{tabular}{|l|l|l|l|}
\hline La Tercera & $\begin{array}{l}\text { "Lagos desafía a Perú a solucionar el tema } \\
\text { marítimo en tribunal internacional" }\end{array}$ & $\begin{array}{l}\text { sábado 5 de } \\
\text { noviembre de 2005 }\end{array}$ & Portada \\
\hline El Mercurio & $\begin{array}{l}\text { "Crisis con Perú amenaza opción marítima } \\
\text { de Bolivia" }\end{array}$ & $\begin{array}{l}\text { domingo 6 de } \\
\text { noviembre de 2005 }\end{array}$ & Portada \\
\hline La Tercera & $\begin{array}{l}\text { "Ex canciller peruano fue ideólogo en } \\
\text { proyecto que generó crisis Lima-Santiago" }\end{array}$ & $\begin{array}{l}\text { domingo 6 de } \\
\text { noviembre de 2005 }\end{array}$ & Portada \\
\hline
\end{tabular}

